\title{
POSTNATAL DEVELOPMENT AND SEXUAL DIFFERENTIATION OF PIG HYPOTHALAMIC NUCLEI
}

\author{
Frank J.C.M. van Eerdenburg ${ }^{1}$ and Dick F. SwaAb ${ }^{2}$ \\ ${ }^{1}$ Department of Functional Morphology, Fac. Veterinary Science, University of Utrecht, \\ Yalelaan 1, Utrecht, The Netherlands, and ${ }^{2}$ Netherlands Institute for Brain Research, \\ Meibergdreef 33, $1105 \mathrm{AZ}$ Amsterdam, The Netherlands
}

(Received 30 August 1993; in final form 10 November 1993)

\begin{abstract}
SUMMARY
The postnatal development of some nuclei in the hypothalamus of the pig is described in relation to sexual differentiation. The vasopressin and oxytocin containing nucleus (VON), a nucleus that has only been described in the pig to date, showed a twofold increase in neuron number and volume during puberty in both sexes. After puberty, this increase in neuron number continued in the females, resulting in a VON that is twice as large in females as in males. The supraoptic nucleus (SON) does not show an increase in neuron number during puberty but in females an increase after puberty is seen, resulting in a sexual dimorphism of the SON in adulthood. Experiments showed that the number of neurons of the VON can be influenced by gonadal steroids. This study confirms that sexual differentiation of the hypothalamus occurs much later in the pig than reported in any other mammalian species so far.
\end{abstract}

Keywords-Swine; Vasopressin- and oxytocin-containing nucleus; Supraoptic nucleus; Testosterone; Sexual dimorphism; Puberty.

\section{INTRODUCTION}

Although RATS AND mice are the most intensively studied mammalian species in the laboratory, development of their brain and behaviour in relation to the moment of birth is certainly not representative for all mammalian species. Primates and pigs have far more mature brains at birth than rodents do (Querido \& Swaab, 1975). A comparable developmental stage of the brain at birth and the relatively long interval between birth and puberty in pigs makes it an interesting species to study during postnatal development and sexual differentiation in relation to human development.

Due to selective breeding, the domestic pig has changed considerably during the past decades. In 1850, for example, the average bodyweight of an adult domestic pig was 40 $\mathrm{kg}$, which was reached in 3-4 years (W.O. Sack, personal communication). Nowadays, adult pigs have a bodyweight of over $250 \mathrm{~kg}$. Most of the animals, however, never reach this weight because they are slaughtered at an age of 6 mo at a weight of $80-100 \mathrm{~kg}$.

Address correspondence and reprint requests to: Frank J.C.M. van Eerdenburg at his present address: Department of Herd Health and Reproduction, Fac. Veterinary Science, University of Utrecht, Yalelaan 7, 3584 CL Utrecht, The Netherlands. 
These changes have been brought about by selection on both speed of growth and adult size. Along with this selection, the onset of puberty has become precocious. Male pigs reach now puberty at an age of 20-30 weeks (Flor-Cruz \& Lapwood, 1978; Lunstra et al., 1986), while their teeth mature between 12 and 15 mo and the ossification process continues until 12-42 mo, depending on the particular bone type investigated (Sisson \& Grossman, 1975). In the present paper, the term "puberty" is therefore only used with regard to sexual maturation.

The insight that hormones were involved in the sexual differentiation of the reproductive organs, as pointed out by Bouin and Ancel (1903), was followed in the 1930s by postulated sex differences in the pituitary (Pfeiffer, 1936). Harris and Jacobson (1952) were the first to suggest that sex differences in behaviour and endocrine functions originate from the hypothalamus, and that the hypothalamus might become differentiated under the influence of testosterone (cf. Fishman \& Breedlove, 1988). At the end of the 1950s, Phoenix et al. (1959) confirmed earlier experiments by Dantchakoff (1938) by showing that sex hormones, when given early during development, had permanent effects upon behaviour. It took until 1966 before Pfaff reported the first neuromorphological sex differences, that is, differences in cell size in a number of brain areas, including the preoptic area of the rat hypothalamus. Pfaff (1966) also suggested an important role for neonatal testosterone in sexual differentiation of the brain. Although since then sex differences have been described in many brain areas and on all levels of complexity, one of the most obvious sexually different structures in the brain is still the sexually dimorphic nucleus of the preoptic area of the rat (SDN) that was found in 1978 by Gorski and his co-workers. After this discovery, similar sexually dimorphic hypothalamic structures were described in other species (Baum, 1986; Bleier et al., 1982; Breedlove, 1992), including humans (Swaab \& Fliers, 1985). In all of these species, the sexually dimorphic structures in the preoptic area are larger in males than in females. This sex difference in size is thought to be brought about by increased neuronal death in females during development (Swaab \& Hofman, 1988). A similar mechanism is supposed to take place in rat spinal cord motorneurons of the bulbocavernosis musculature (Nordeen et al., 1985). The neonatal testosterone surge is thought to be of major importance in determining whether the SDN remains large or becomes smaller (Rhees et al., 1990a, 1990 b) by protecting SDN neurons from programmed cell death.

\section{TESTOSTERONE LEVELS DURING DEVELOPMENT IN MALE PIGS}

Testosterone levels in male pigs show three elevations during development (Fig. 1). The first elevation is around Day 40-45 of the 114-day gestational period (Ford et al., 1980). This surge is essential for the differentiation of the gonads and genital organs. A second elevation in plasma testosterone is seen immediately after birth (Ford, 1990; Meusy-Desolle, 1975). In other mammalian species, this neonatal testosterone surge is thought to be important for the sexual differentiation of the hypothalamus and behaviour (Arai \& Gorski, 1968; Tobet et al., 1986; Toran-Allerand, 1978), but such a relationship has so far not been established for the pig.

Before puberty, the pig testes already undergo drastic changes (Van Straaten \& Wensing, 1978). Around puberty, Allrich et al. (1983) and Lunstra et al. (1986) found increases in pig Leydig cell volume and sensitivity for HCG that were reversed after puberty. These transient changes of the Leydig cells are reflected in peripheral testosterone levels. 


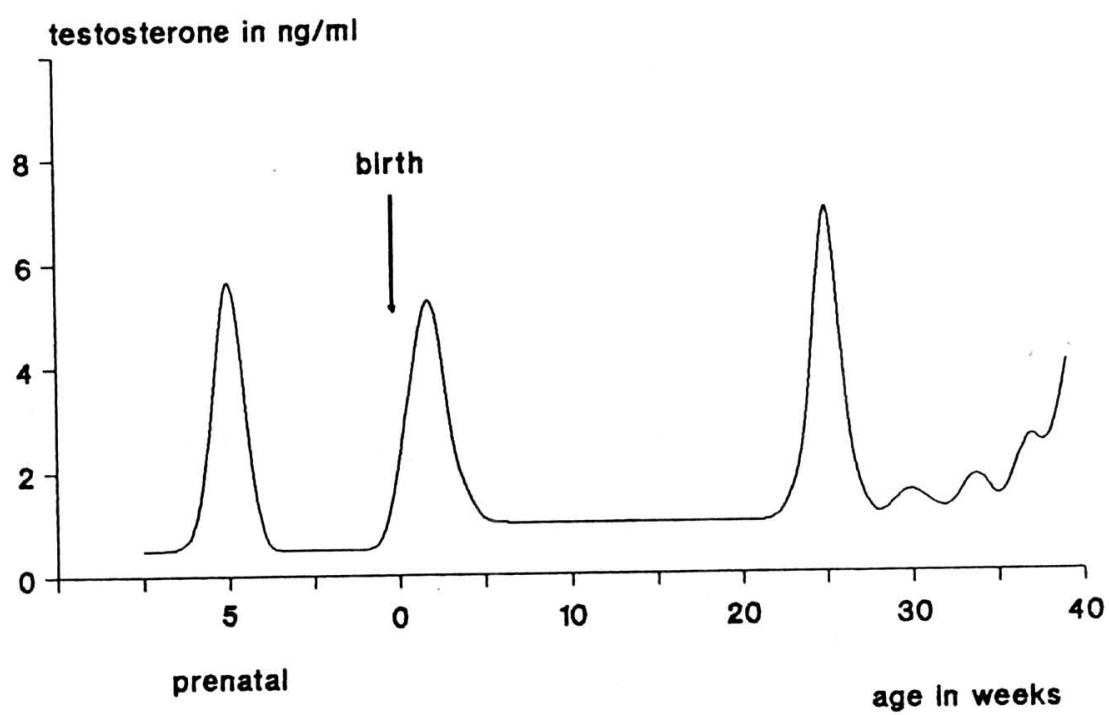

Fig. 1: Testosterone levels of male pigs during development. These levels are not absolute, but compiled from a number of studies (Andresen, 1976; Colenbrander et al., 1978; Elsaesser et al., 1976; Flor-Cruz \& Lapwood, 1978; Ford et al., 1980; Gray et al., 1971; Lapwood \& Flor-Cruz, 1978; Liptrap et al., 1986; Meusy-Desolle, 1975; Schwarzenberger et al., 1993; Tan \& Raeside, 1980; Trudeau et al., 1992; Van Eerdenburg et al., 1991a).

Trudeau et al. (1992) reported low testosterone levels until 24 weeks postnatally, followed by a short surge, after which low testosterone levels were observed again. Flor-Cruz and Lapwood (1978) reported a similar, though longer lasting, surge at 20 weeks, and observed the appearance of the first spermatozoa in epididymal tubules 6 days later. We were able to document a similar transient testosterone surge at 25 weeks (Van Eerdenburg et al. 1991a). Since this transient surge during puberty coincides with the determination of sexual behaviour, a causal relationship between these two phenomena seems likely.

\section{SEXUAL DIFFERENTIATION OF BRAIN AND BEHAVIOUR IN THE PIG}

Studies by Adkins-Regan et al. (1989) and Ford $(1982,1990)$ show that sexual behaviour of the pig is defeminized, due to testosterone, between 16 and 32 weeks of age and cannot be reversed after this age. Since testosterone is an important factor in the defeminization process in other species (Tobet et al., 1986; Toran-Allerand, 1978) the third, pubertal, testosterone peak is assumed to be important for the defeminization of the hypothalamus of the pig, too. A morphological marker in the hypothalamus, like the SDN, could be useful in testing this hypothesis.

During the search for sexually dimorphic structures in the pig hypothalamus, a vasopressin and oxytocin containing nucleus (VON) was found that showed a remarkably late increase in neuron number and development of sexual dimorphism (Van Eerdenburg et al., 1990; Van Eerdenburg \& Swaab, 1991) (Figs. 2 and 3). The cytoarchitecture and peptide content of the VON suggest a close relationship with the hypothalamoneurohypophyseal system (HNS), which is involved in a number of different processes, for example, salt and water balance, stress response, and reproduction (cf. Gash \& Boer, 


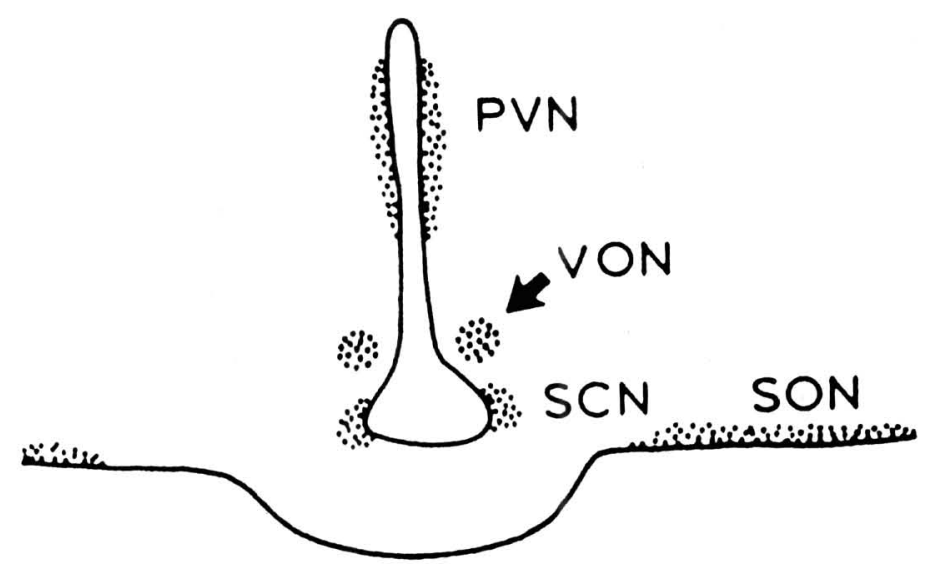

FIG. 2: Topography of the pig hypothalamus. III = third ventricle, $\mathrm{PVN}=$ paraventricular nucleus, $\mathrm{SCN}=$ suprachiasmatic nucleus, $\mathrm{SON}=$ supraoptic nucleus, $\mathrm{VON}=$ vasopressin and oxytocin containing nucleus. (Reproduced with permission from Van Eerdenburg et al., 1990.)

1987). Two of the major nuclei of the HNS are the supraoptic nucleus (SON) and the paraventricular nucleus (PVN). Both nuclei contain magnocellular neurons that are immunoreactive for vasopressin (VP) or oxytocin (OXT) (Swaab et al., 1975). In a number of mammalian species, distinct accessory magnocellular nuclei of the SON and/or PVN have been described that could be homologous to the VON, such as the nucleus circularis (Peterson, 1966), which is thought to be involved in osmoregulation in the rat (Hatton, 1976) and dominant-subordinate behaviour in the hamster (Ferris et al., 1989). However, the VON is not homologous to the nucleus circularis, since we found another nucleus in the pig, that is located more laterally than the VON in the same area as the nucleus circularis in the rat (Van Eerdenburg et al., 1992a). In the mouse, the mouse accessory nucleus has been described (Castel \& Morris, 1988) that is possibly homologous to the pig VON because of its location, cytoarchitecture and peptide content, but its function has not yet been investigated. In the rat, Altman and Bayer (1986) mention intermediate magnocellular nuclei that are located between the PVN and SON. These accessory nuclei are relatively small in comparison to the SON and PVN and, although they contain both VP and OXT immunoreactive neurons, they are probably not homologous to the pig VON on the basis of their localization and organization of the neurons around bloodvessels. In the pig, similar, small accessory magnocellular nuclei are found that have a tubular shape around bloodvessels (Van Eerdenburg et al., 1990).

The development of the number of neurons and volume of the VON during the postnatal period are presented in Fig. 3. After an initial decrease in neuron number in the neonatal period, an increase was found during puberty in both sexes. After puberty, this increase continues in the female, thus resulting in sexual dimorphism of this nucleus in adulthood. This sexual dimorphism is not similar to any of the previously described dimorphisms in other species for three reasons: (1) the female has a larger VON than the male pig. Only two of the hypothalamic sexual dimorphisms that have been described to date have a larger female nucleus: the rat anteroventral periventricular nucleus (Bleier et al., 1982; Bloch \& Gorski, 1988) and the parastrial nucleus (Del Abril et al., 1990). (2) The difference in neuron number is not due to cell death, but to an increase in neuron number in the 

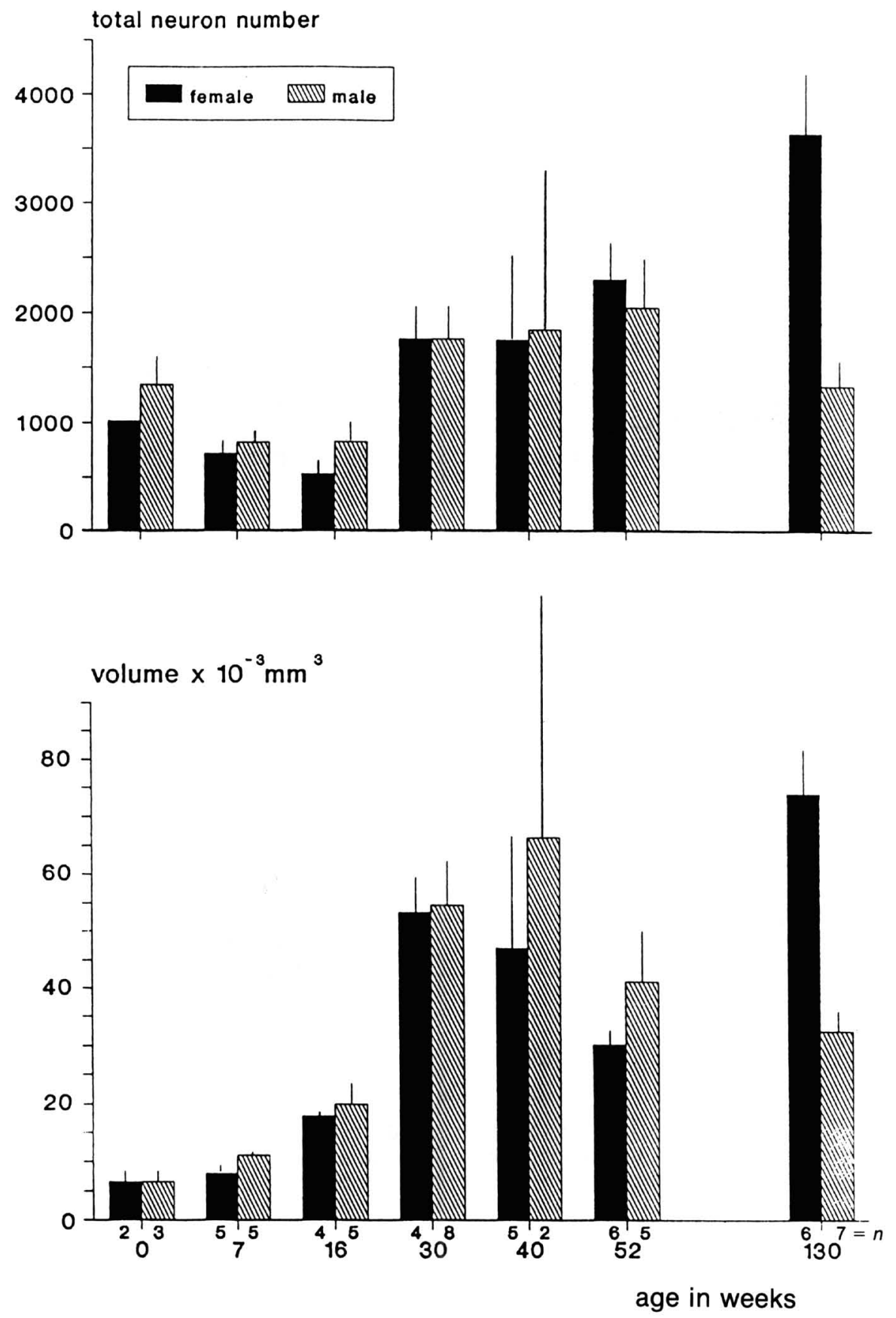

FIG. 3: Neuron number and volume (+ SEM) of the vasopressin and oxytocin containing nucleus (VON) of the pig hypothalamus during postnatal development. (Reproduced with permission from Van Eerdenburg \& Swaab, 1991.) 

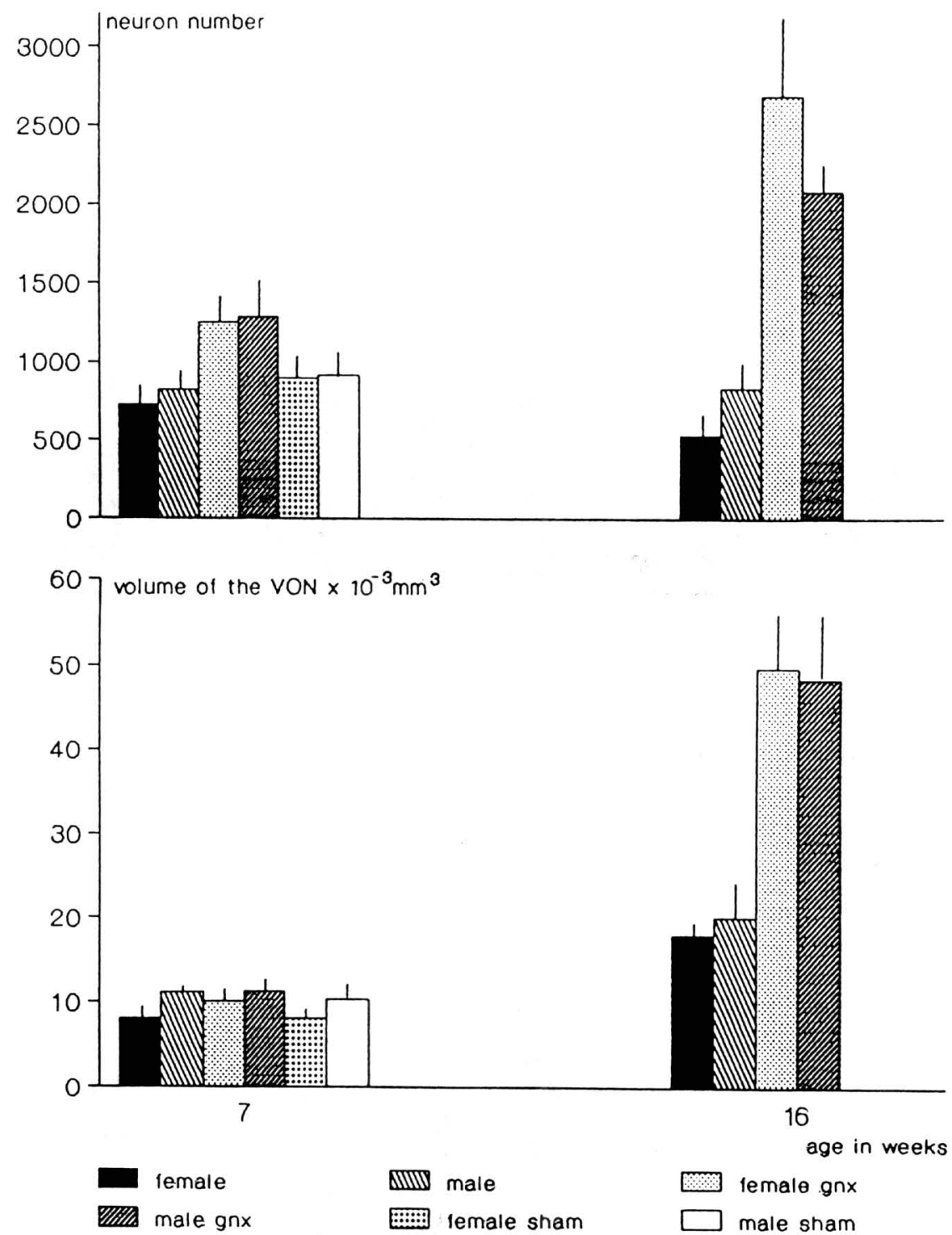

FIG. 4: Neuron number (+ SEM) of the vasopressin and oxytocin containing nucleus (VON) of the pig hypothalamus after neonatal gonadectomy at 7 and 16 weeks. (Reproduced with permission from Van Eerdenburg et al., 1991b.)

VON of the female pig. (3) The sex difference becomes apparent only after puberty, that is, well after the sexual differentiation of behaviour.

Since the neonatal testosterone surge is an important factor in sexual differentiation of other mammalian species, the possible role of this hormone surge in the sexual differentiation of the VON was investigated. Male and female pigs were gonadectomized within $12 \mathrm{~h}$ after birth to prevent an influence of the neonatal testosterone surge, which occurs immediately after, but not before birth (Meusy-Desolle, 1975). The animals were killed at 7 and 16 weeks postnatally (Van Eerdenburg et al., 1991b; Fig. 4). In both male 


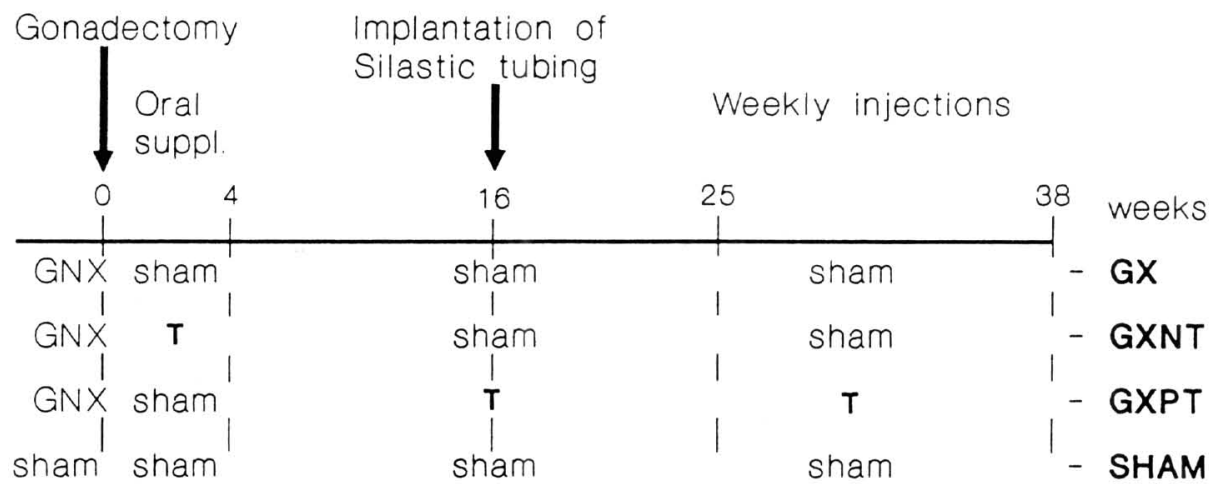

FIG. 5: Experimental design for testosterone substitution in neonatally gonadectomized pigs. Abbreviations: $\mathrm{GNX}=$ gonadectomy, $\mathrm{GX}=$ gonadectomized animal without testosterone substitution, GXNT = gonadectomized animal with neonatal testosterone substitution, GXPT = gonadectomized animal with pubertal testosterone substitution, SHAM $=$ animals receiving sham treatment, $\mathrm{T}=$ testosterone substitution. (Reproduced with permission from Van Eerdenburg et al., 1991b.)

and female pigs, the number of neurons increased between 7 and 16 weeks to numbers that are found in intact postpubertal (30 weeks) animals (Fig. 3). Thus, it seemed that the pubertal increase had been advanced by gonadectomy. In another experiment (Van Eerdenburg et al., 1991b), pigs of a different breed were gonadectomized within $12 \mathrm{~h}$ after birth and given testosterone at various ages (see Fig. 5). These animals were all killed at 38 weeks of age (Fig. 6). The group that received testosterone during the pubertal period (GXPT) had a lower number of neurons than the other groups. Thus, testosterone does not seem to have a direct influence on the number of neurons of the VON. During puberty in intact animals, steroid levels rise, and so does the neuron number. The observation that gonadectomy increases neuron numbers seems to be contradictory to the findings around puberty in intact animals (Fig. 3). The same holds for the finding that testosterone treatment during puberty causes the number of neurons to decrease after they have been at postpubertal levels due to neonatal gonadectomy. However, a correlation seems to exist between the neuron number of the VON and the level of gonadotropic hormones. During the neonatal period, luteinizing hormone (LH) levels are high in both males and females (Colenbrander et al., 1977; Ponzilius et al., 1986); so is the number of neurons in the VON (Fig. 3). After a few weeks, LH levels drop and remain low until the beginning of puberty ( 16 weeks); so does the number of neurons in the VON. During puberty, LH levels start to fluctuate and tend to rise; so does the number of VON neurons. When the animals were gonadectomized and not given testosterone, $\mathrm{LH}$ levels remained low until 7 weeks of age because the feedback mechanism of testosterone becomes functional only after 8 weeks of age (Elsaesser et al., 1975). When it does, LH levels rise and so does the number of neurons in the VON, as can be seen in the neonatally gonadectomized pigs at 16 weeks of age (Fig. 4). Because of the constant treatment with testosterone during puberty in our experiment, LH levels were very low. This might explain the difference between the pubertally treated (GXPT) and the intact (sham) animals. However, this does not fully explain the sex difference that develops after puberty. Both males and females have fluctuating levels of LH after puberty (Ellendorff et al., 1975; Foxcroft \& Van de Wiel, 1982; Liptrap et al., 1986; Parvizi 
total neuron number of the VON
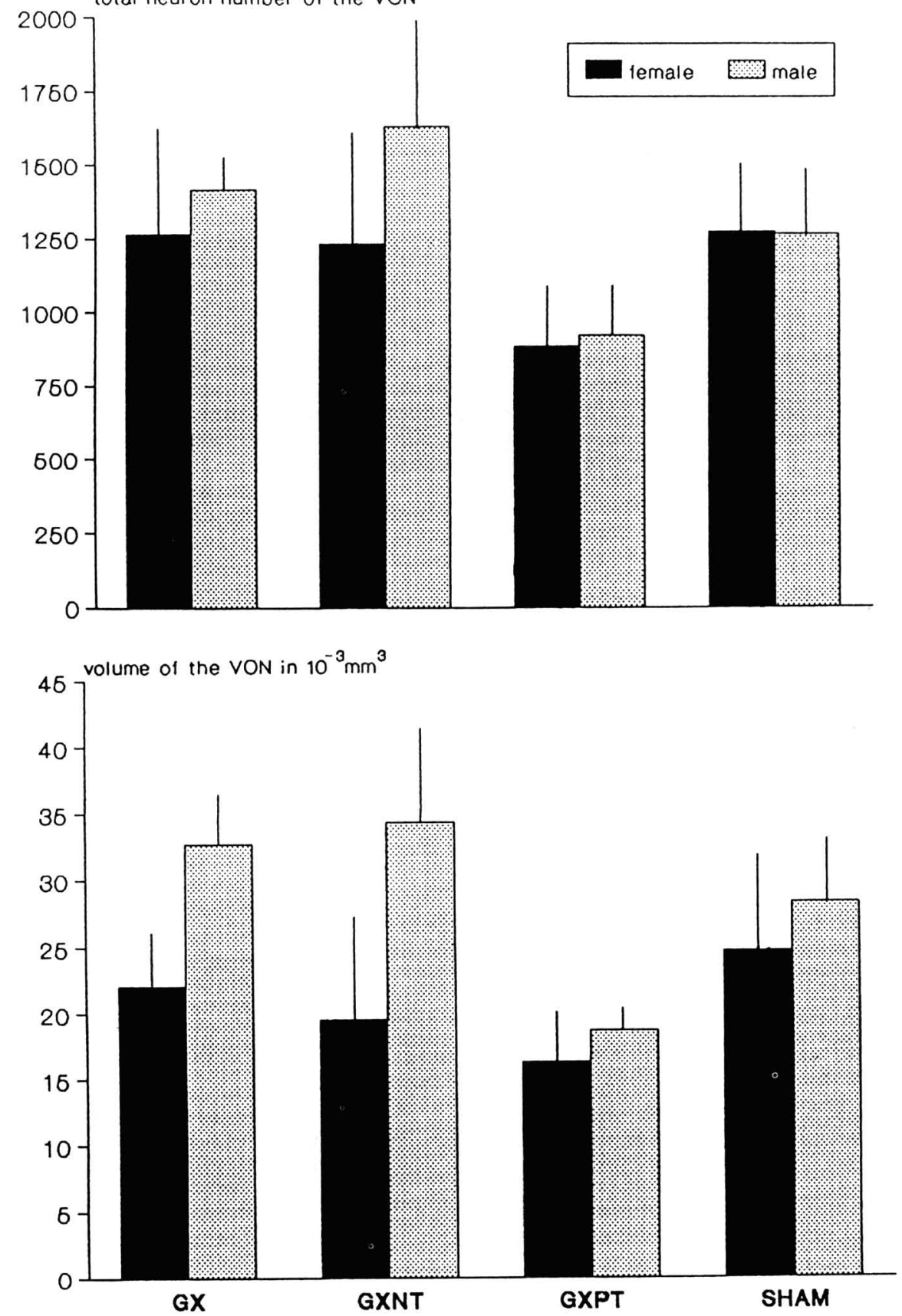

FIG. 6: Neuron number (+ SEM) of the vasopressin and oxytocin containing nucleus (VON) of the pig hypothalamus after neonatal gonadectomy and testosterone substitution according to the scheme of Fig. 5. Age of the animals was 38 weeks (postpubertal). (Reproduced with permission from Van Eerdenburg et al., 1991b.) 
et al., 1976). Unfortunately different breeds and assays have been used in these studies so that we cannot simply compare the LH levels in both sexes in these studies. In addition, information on brain receptors for gonadotropic hormones is lacking in the pig. The causal factor involved in these changes in neuron number of the VON therefore remains unclear and indirect effects (e.g. mediated by neuropeptides) should certainly be considered.

Another nucleus of the HNS, the SON, was also found to be sexually dimorphic in pigs (Fig. 7). The number of neurons in the SON is constant during development in species like rats and humans (Crespo et al., 1990; Goudsmit et al., 1992; Sartin \& Lamperti, 1985). In pigs, there is an increase in SON neuron number after puberty in females, whereas the number in males remains constant (Van Eerdenburg et al., 1992b). An increase in neuron number during puberty as seen in the VON is not apparent in the SON, thus underscoring the own identity of the VON. A remarkable finding was that, following neonatal gonadectomy, the number of SON neurons decreased in both gonadectomized and sham-operated animals (Fig. 8) (Van Eerdenburg et al., 1992b). This observation is puzzling since HNS neurons are believed to be generated relatively early during gestation (Altman \& Bayer, 1986; Goudsmit et al., 1992; Van Eerdenburg \& Rakic, unpublished). Neither gonadectomy nor testosterone treatment during puberty altered the number of neurons in the SON (Van Eerdenburg et al., 1992b). Therefore, the reason for the increase in SON neuron number after puberty in females remains unclear. One might speculate that the fact that these pigs have had several large litters of fast growing piglets, which need large amounts of milk, may be a causal factor in this respect, but further experimental data are needed.

So far we discussed two sexually dimorphic nuclei in the pig hypothalamus that are not homologous to the SDN of the preoptic area as described by Gorski et al. (1978). The SDN does not contain vasopressin or oxytocin and is located more rostrally than the VON. The sexually dimorphic structures of the hypothalamus in the different species do not contain a known specific marker what makes it difficult to determine homology. However, the neurons of the rat SDN contain estrogen receptors (Simerly et al., 1990). When we stained estrogen receptors in the pig hypothalamus, we discovered a group of estrogen receptor positive cells that is localized lateral from the organum vasculosum of the lamina terminalis (OVLT). In females this cell group, that might be homologous to the rat SDN, is substantially larger than in males at the end of puberty (Chouham et al., unpublished). However, since it has not been distinguished so far in conventionally stained material, no morphometric analysis has been performed to date.

\section{CONCLUSIONS}

In pigs, sexual differentiation occurs much later than in many other mammalian species. Endocrinological and behavioural studies revealed that until puberty, and even during puberty, differentiation of sexual behaviour is still reversible. The data presented reinforce the previous behavioural studies with morphological data. At least two vasopressin and oxytocin containing nuclei of the HNS are sexually dimorphic in neuron number, that is, the SON and VON. At the end of puberty, sexual dimorphism in these nuclei is still not evident, but between puberty and adulthood, the neuron number increases in females. The possible homologue of the SDN in other species is also substantially larger in female than in male pigs. This last sexual dimorphism is already evident by the end of puberty. 

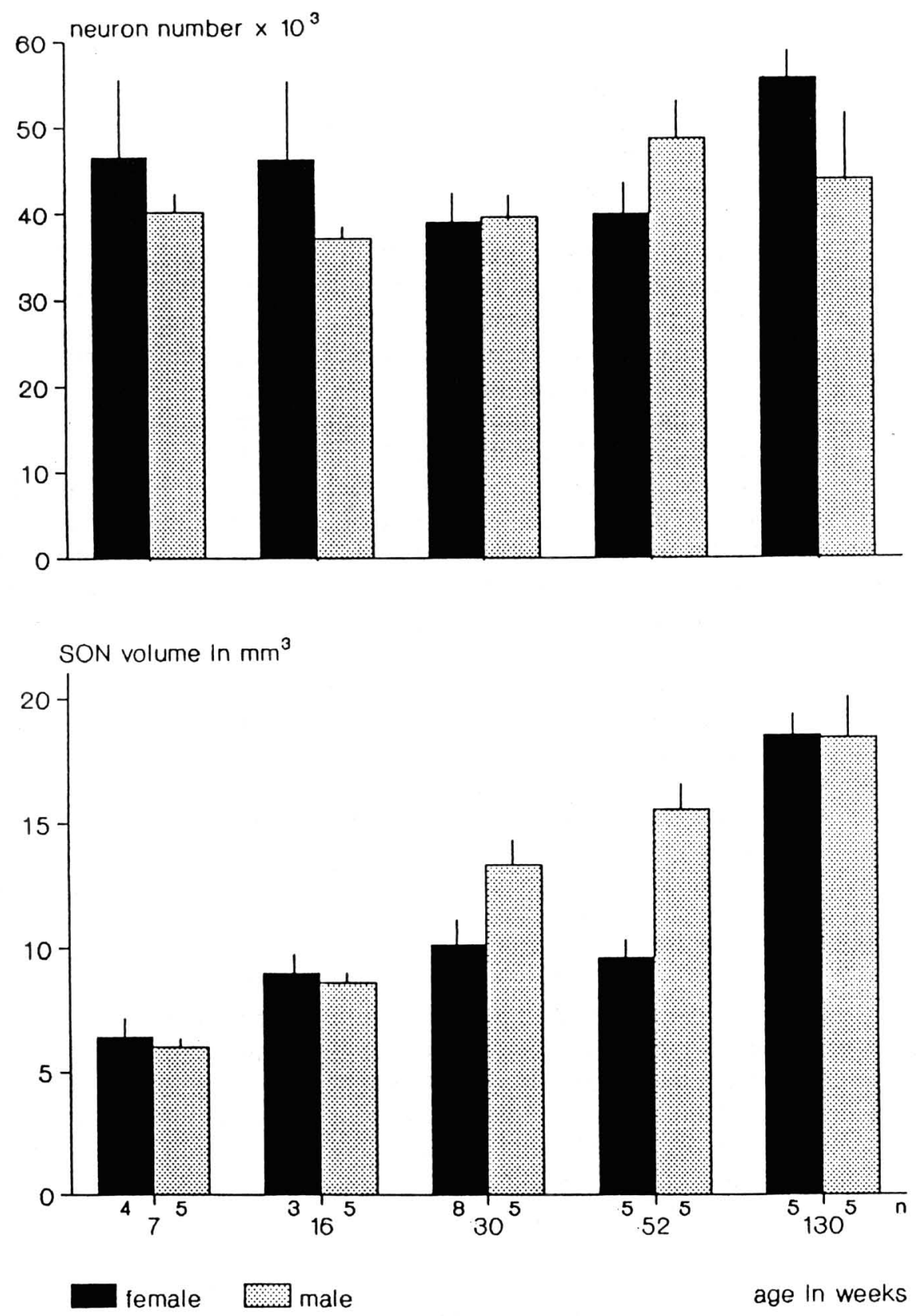

FIG. 7: Neuron number and volume (+ SEM) of the supraoptic nucleus (SON) of the pig hypothalamus during postnatal development. (Reproduced by permission of the Journal of Endocrinology Ltd; Van Eerdenburg et al., 1992b.) 

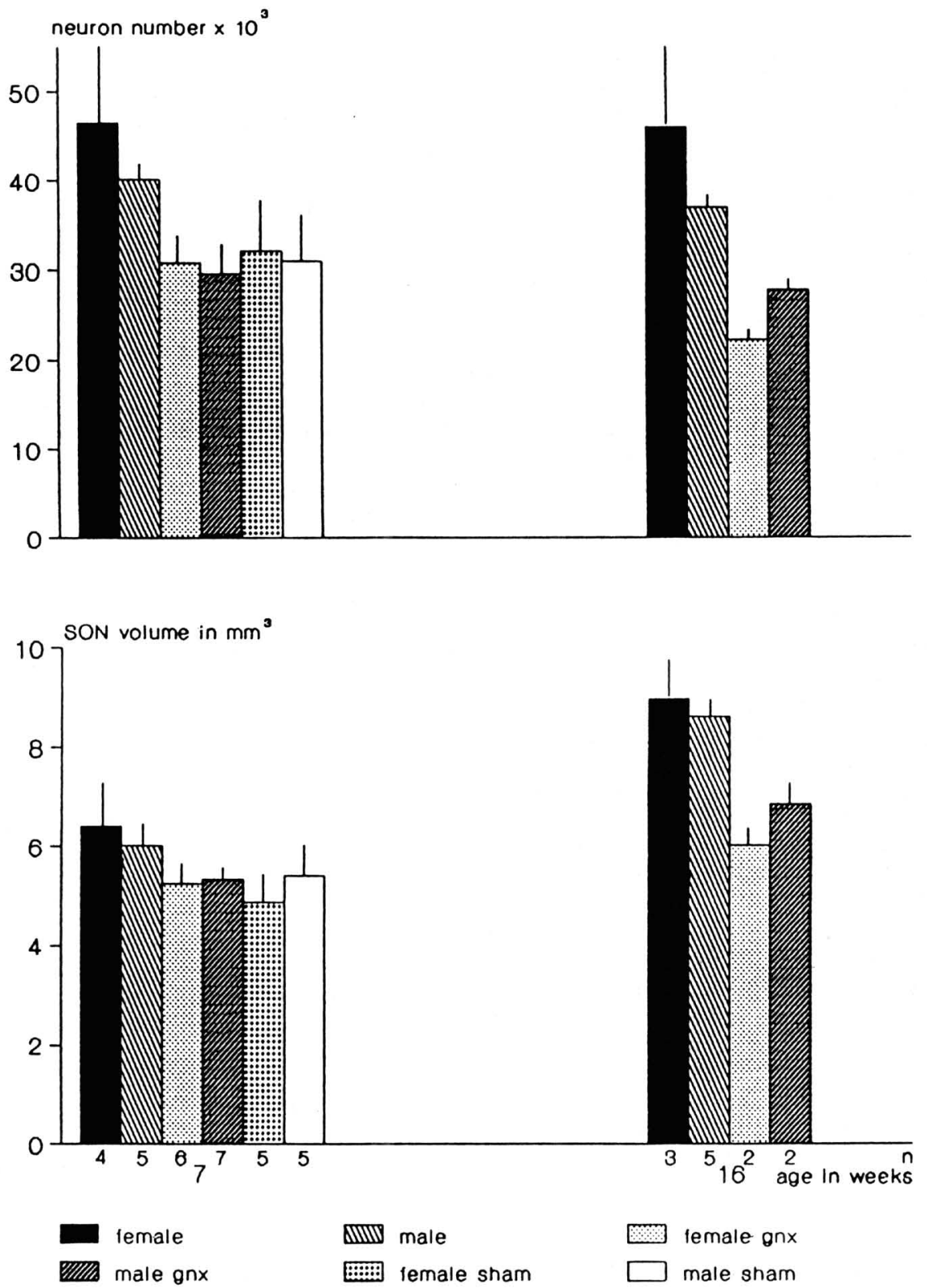

FIG. 8: Neuron number and volume (+ SEM) of the supraoptic nucleus (SON) of the pig hypothalamus after neonatal gonadectomy at 7 and 16 weeks. (Reproduced by permission of the Journal of Endocrinology Ltd; Van Eerdenburg et al., 1992b.) 


\section{REFERENCES}

Adkins-Regan E, Orgeur P, Signoret JP (1989) Sexual differentiation of reproductive behaviour in pigs: Defeminizing effects of prepubertal estradiol. Horm Behav 23:290-303.

Allrich RD, Christenson RK, Ford JJ, Zimmerman DR (1983) Pubertal development of the boar: Age-related changes in testicular morphology and in vitro production of testosterone and estradiol-17ß. Biol Reprod 28:902-909.

Altman J, Bayer SA (1986) The development of the hypothalamus. Adv Anat Embryol Cell Biol 100:46-94.

Andresen O (1976) Concentrations of fat and plasma $5 \alpha$-androstenone and plasma testosterone in boars selected for rate of body weight gain and thickness of backfat during growth, sexual maturation and after mating. J Reprod Fert 48:51-59.

Arai Y, Gorski RA (1968) Critical exposure time for androgenization of the developing hypothalamus in the female rat. Endocrinology 82:1010-1014.

Baum M (1986) Gender dimorphism in brain. Natl Inst Drug Abuse Res Monogr Ser 65:49-57.

Bleier R, Byne W, Siggelkow I (1982) Cytoarchitectonic sexual dimorphisms of the medial preoptic areas in guinea pig, rat, hamster and mouse. J Comp Neurol 212:118-130.

Bloch GJ, Gorski RA (1988) Estrogen/progesterone treatment in adulthood affects the size of sevral components of the medial preoptic area in the male rat. J Comp Neurol 275:613-622.

Bouin P, Ancel P (1903) Sur la signification de la glande interstitielle du testicule embryonnaire. C R Soc Biol 55:1682-1684.

Breedlove SM (1992) Sexual dimorphism in the vertebrate nervous system. J Neurosci 12:4133-4142.

Castel M, Morris JF (1988) The neurophysin-containing innervation of the forebrain of the mouse. Neuroscience 24:937-966.

Colenbrander B, De Jong FH, Wensing CJG (1978) Changes in serum testosterone concentrations in the male pig during development. J Reprod Fertil 53:377-380.

Colenbrander B, Kruip ThAM, Dieleman SJ, Wensing CJG (1977) Changes in serum LH concentrations during normal and abnormal sexual development in the pig. Biol Reprod 17:506-513.

Crespo D, Ramos J, Gonzalez C, Fernandez-Viadero C (1990) The supraoptic nucleus: A morphological and quantitative study in control and hypophysectomized rats. J Anat 169:115-123.

Dantchakoff V (1938) Roles des hormones dans les manifestations des instincts sexuels. C R Acad Sci (Paris) 206:945-947.

Del Abril A, Segovia S, Guillamon A (1990) Sexual dimorphism in the parastrial nucleus of the rat preoptic area. Dev Brain Res 52:11-15.

Ellendorff F, Parvizi N, Pomerantz DK, Hartjen A, Konig A, Smidt D, Elsaesser F (1975) Plasma luteinizing hormone and testosterone in the adult male pig: 24 hour fluctuations and the effect of copulation. J Endocrinol 67:403-410.

Elsaesser F, Ellendorff F, Pomerantz DK, Parvizi N, Smidt D (1976) Plasma levels of luteinizing hormone, progesterone, testosterone and $5 \alpha$-dihydrotestosterone in male and female pigs during sexual maturation. J Endocrinol 68:347-348.

Elsaesser F, Parvizi N, Konig A (1975) Feedback sensitivity of LH secretion to cryptone (Cy), testosterone $(\mathrm{T})$ and estradiol-17 $\beta(\mathrm{E})$ in neonatal and pubertal male miniature pig. Acta Endocrinol (Kbh) 199:354.

Ferris CF, Axelson JF, Roberge AM, Martin LF (1989) Vasopressin immunoreactivity in the anterior hypothalamus is altered during the establishment of dominant/subordinate relationships between hamsters. Neuroscience 29:675-683.

Fishman RB, Breedlove SM (1988) Sexual dimorphism in the developing nervous system. In: Meisami E, Timiras PS (Eds) Handbook of Human Growth and Developmental Biology, Vol I, Part C. CRC Press, Boca Raton, Florida, pp 45-57.

Flor-Cruz SV, Lapwood KR (1978) A longitudinal study of pubertal development in boars. Int J Androl 1:317-330.

Ford JJ (1982) Testicular control of defeminization in male pigs. Biol Reprod 27:425-430.

Ford JJ (1990) Differentiation of sexual behaviour in pigs. J Reprod Fert Suppl 40:311-321.

Ford JJ, Christenson RK, Maurer RR (1980) Serum testosterone concentrations in embryonic and fetal pigs during sexual differentiation. Biol Reprod 23:583-587.

Foxcroft GR, Van de Wiel DFM (1982) Endocrine control of the oestrus cycle. In: Cole DJA, Foxcroft GR (Eds) Control of Pig Reproduction, Butterworth Sci., London, pp 161-177. 
Gash DM, Boer GJ (1987) Vasopressin: Principles and Properties. Plenum Press, New York.

Gorski RA, Gordon JH, Shryne JE, Southam AM (1978) Evidence for a morphological sex difference withir the medial preoptic area of the rat brain. Brain Res 148:333-346.

Goudsmit E, Neijmeijer-Leloux A, Swaab DF (1992) The human hypothalamo-neurohypophyseal system in relation to development, aging and Alzheimer's disease. In: Swaab DF, Hofman MA, Mirmiran M, Ravid R, Van Leeuwen FW (Eds) Progress in Brain Research 93:237-248.

Gray RC, Day BN, Lasley JF, Tribble LF (1971) Testosterone levels of boars at various ages. J Anim Sci 33:124-126.

Harris GW, Jacobson D (1952) Functional grafts of the anterior pituitary gland. Proc R Soc Lond (Biol) 139:263.

Hatton GI (1976) Nucleus circularis: Is it an osmoreceptor in the brain? Brain Res Bull 1:123-131.

Lapwood KR, Flor-Cruz SV (1978) Luteinizing hormone and testosterone secretory profiles of boars: Effects of stage of sexual maturation. Theriogenology 10:293-306.

Liptrap RM, Doble E, Cheng KW (1986) Plasma concentration profiles of gonadotropins and testosterone in the adult boar. Can J Vet Res 50:427-432.

Lunstra DD, Ford JJ, Christenson RK, Allrich RD (1986) Changes in leydig cell ultrastructure and function during pubertal development in the boar. Biol Reprod 34:145-158.

Meusy-Dessolle N (1975) Variations quantitatives de la testosterone plasmatique chez le porc male de la naissance a l'age adulte. C R Hebd Seanc Acad Sci (Paris) D281:1875-1878.

Nordeen EJ, Nordeen KW, Sengelaub DR, Arnold AP (1985) Androgens prevent normally occuring cell death in a sexually dimorphic spinal nucleus. Science 229:671-673.

Parvizi N, Elsaesser F, Smidt D, Ellendorff F (1976) Plasma luteinizing hormone and progesterone in the adult female pig during the oestrous cycle, late pregnancy and lactation, and after ovariectomy and pentobarbitone treatment. J Endocrinol 69:193-203.

Peterson RP (1966) Magnocellular neurosecretory centres in the rat hypothalamus. J Comp Neurol 128:181-190.

Pfaff DW (1966) Morphological changes in the brains of adult male rats after neonatal castration. J Endocrinol 36:415-416.

Pfeiffer CA (1936) Sexual differences of the hypophyses and their determination by the gonads. Am J Anat 58:195-225.

Phoenix ChH, Goy RW, Gerall AA, Young WC (1959) Organizing action of prenatally administered testosterone propionate on the tissues mediating mating behavior in the female guinea pig. Endocrinology 65:369-382.

Ponzilius KH, Parvizi N, Elsaesser F, Ellendorff F (1986) Ontogeny of secretory patterns of LH release and effects of gonadectomy in the chronically catheterized pig fetus and neonate. Biol Reprod 34:602-612.

Querido A, Swaab DF (1975) Brain Development and Thyroid Deficiency. North-Holland Publishing Co., Amsterdam, p 39.

Rhees RW, Shryne JE, Gorski RA (1990a) Termination of the hormone sensitive period for differentiation of the sexually dimorphic nucleus of the preoptic area in male and female rats. Dev Brain Res 52:17-23.

Rhees RW, Shryne JE, Gorski RA (1990b) Onset of the hormone-sensitive perinatal period for sexual differentiation of the sexually dimorphic nucleus of the preoptic area. J Neurobiol 21:781-786.

Sartin JL, Lamperti AA (1985) Neuron numbers in hypothalamic nuclei of young, middle-aged and aged male rats. Experientia 41:109-111.

Schwartzenberger F, Toole GS, Christie HL, Raeside JI (1993) Plasma levels of several androgens and estrogens from birth to puberty in male domestic pigs. Acta Endocrinol 128:173-177.

Simerly RB, Chang C, Muramatsu M, Swanson LW (1990) Distribution of androgen and estrogen receptor mRNA-containing cells in the rat brain: An in situ hybridization study. J Comp Neurol 294:76-95.

Sisson S, Grossman JD (1975) Porcine osteology. In: Getty R. (Ed) The Anatomy of the Domestic Animals. Saunders, Philadelphia, pp 1016-1031.

Swaab DF, Fliers E (1985) A sexually dimorphic nucleus in the human brain. Science 228:1112-1115.

Swaab DF, Hofman MA (1988) Sexual differentiation of the human hypothalamus: Ontogeny of the sexually dimorphic nucleus of the preoptic area. Dev Brain Res 44:314-318. 
Swaab DF, Nijveldt F, Pool CW (1975) Distribution of oxytocin and vasopressin in the rat supraoptic and paraventricular nucleus. J Endocrinol 67:461-462.

Tan HS, Raeside JI (1980) Developmental patterns of plasma dehydroepiandrosterone sulfate and testosterone in male pigs. Anim Reprod Sci 3:73-81.

Tobet SA, Zahnisher DJ, Baum MJ (1986) Differentiation in male ferrets of a sexually dimorphic nucleus of the preoptic/anterior hypothalamic area requires prenatal estrogen. Neuroendocrinology 44:299-308.

Toran-Allerand CD (1978) Gonadal hormones and brain development: cellular aspects of sexual differentiation. Am Zool 18:553-565.

Trudeau VL, Meijer JC, Erkens JHF, Van de Wiel DFM, Wensing CJG (1992) Pubertal development in the male pig: Effects of treatment with a long-acting gonadotropin-releasing hormone agonist on plasma LH, FSH, and testosterone. Can J Vet Res 56:102-109.

Van Eerdenburg FJCM, Lugard-Kok CMJE, Dieleman SJ, Swaab DF, Wensing CJG (1991a) Testosterone levels in boars during puberty. In: Van Eerdenburg FJCM (Ed) Postnatal Development of Some Nuclei in the Pig Hypothalamus. Thesis, Utrecht, The Netherlands, pp 87-94.

Van Eerdenburg FJCM, Lugard-Kok CMJE, Dieleman SJ, Bevers MM, Swaab DF (1991b) Influence of gonadectomy and testosterone supplementation on the postnatal development of the vasopressin and oxytocin containing nucleus of the pig hypothalamus. Neuroendocrinology 54:580-586.

Van Eerdenburg FJCM, Lugard-Kok CMJE, Swaab DF (1992b) The supraoptic nucleus in the pig hypothalamus: Postnatal development and the effect of gonadal steroids. J Endocrinol 134:19-25.

Van Eerdenburg FJCM, Poot P, Molenaar GJ, Van Leeuwen FW, Swaab DF (1990) A vasopressin and oxytocin containing nucleus in the pig hypothalamus that shows neuronal changes during puberty. J Comp Neurol 310:138-146.

Van Eerdenburg FJCM, Swaab DF (1991) Increasing neuron numbers in the vasopressin and oxytocin containing nucleus of the adult female pig hypothalamus. Neurosci Lett 132:85-88.

Van Eerdenburg FJCM, Swaab DF, Van Leeuwen FW (1992a) Distribution of vasopressin and oxytocin cells and fibers in the hypothalamus of the domestic pig (Sus scrofa). J Comp Neurol 318:138-146.

Van Straaten HWM, Wensing CJG (1978) Leydig cell development in the testis of the pig. Biol Reprod 17:473-479. 